\title{
Article
}

Mycosphere

\section{A new species of Antrodia (Basidiomycota, Polypores) from China}

\author{
Chen YY, Wu F* \\ Institute of Microbiology, Beijing Forestry University, Beijing 100083, China
}

Chen YY, Wu F 2017 -A new species of Antrodia (Basidiomycota, Polypores) from China. Mycosphere 8(7), 878-885, Doi 10.5943/mycosphere/8/7/4

\begin{abstract}
A new species, Antrodia monomitica sp. nov., is described and illustrated from China based on morphological characters and molecular evidence. It is characterized by producing annual, fragile and nodulose basidiomata, a monomitic hyphal system with clamp connections on generative hyphae, hyaline, thin-walled and fusiform to mango-shaped basidiospores $(6-7.5 \times 2.3-$ $3 \mu \mathrm{m}$ ), and causing a typical brown rot. In phylogenetic analysis inferred from ITS and nLSU rDNA sequences, the new species forms a distinct lineage in the Antrodia s. 1., and has a close relationship with $A$. oleracea.
\end{abstract}

Key words - Fomitopsidaceae - phylogenetic analysis - taxonomy - wood-decaying fungi

\section{Introduction}

Antrodia P. Karst., typified with Polyporus serpens Fr. (=Antrodia albida (Fr.) Donk (Donk 1960, Ryvarden 1991), is characterized by a resupinate to effused-reflexed growth habit, white or pale colour of the context, a dimitic hyphal system with clamp connections on generative hyphae, hyaline, thin-walled, cylindrical to very narrow ellipsoid basidiospores which are negative in Melzer's reagent and Cotton Blue, and causing a brown rot (Ryvarden \& Melo 2014).

Antrodia is a highly heterogeneous genus which is closely related to Fomitopsis P. Karst., Daedalea Pers. and Oligoporus Bref (Bernicchia et al. 2012, Kim et al. 2003, Rajchenberg et al. 2011, Spirin et al. 2012, Yu et al. 2010). Recently studies have divided Antrodia sensu lato into three genera: Antrodia sensu stricto, Fibroporia Parmasto and Amyloporia Bondartsev \& Singer (Bernicchia et al. 2012, Chen et al. 2015b, Chen \& Cui 2016, Cui 2013, Cui \& Dai 2013, Rajchenberg et al. 2011, Spirin et al. 2013, Yu et al. 2010), but there are still several unrelated lineages spread among other brown rot polypores (Han et al. 2016, Ortiz-Santana et al. 2013, Spirin et al. 2013, 2015, 2016).

A recent investigation of Antrodia has been carried out in China, two specimens are identified belonging to Antrodia s. 1., but they are distinguished from any known species. Phylogenetic analysis was performed using the internal transcribed spacer (ITS) regions and nuclear large subunit (nLSU) ribosomal RNA gene regions. Combined with the morphological characters, a new species is described in this study.

\section{Materials \& Methods}

\section{Morphological studies}


The studied specimens are deposited at the herbarium of the Institute of Microbiology, Beijing Forestry University (BJFC). The microscopic procedure follows Li et al. (2014) and Han et al. (2016). Color terms followed Petersen (1996). Spores were measured from sections cut from the tubes. 5\% of measurements were excluded from each end of the range, and were given in parentheses. The following abbreviations were used: $\mathrm{KOH}=5 \%$ potassium hydroxide; IKI $=$ Melzer's reagent; IKI- = neither amyloid nor dextrinoid; $\mathrm{CB}=$ Cotton Blue; $\mathrm{CB}-=$ acyanophilous; $\mathrm{L}=$ mean spore length (arithmetic average of all spores) $\mathrm{W}=$ mean spore width (arithmetic average of all spores); $\mathrm{Q}=$ the ratios of $\mathrm{L} / \mathrm{W} ; \mathrm{n}(\mathrm{a} / \mathrm{b})=$ number of spores (a) measured from given number (b) of specimens.

\section{Molecular study}

A CTAB rapid plant genome extraction kit (Demeter Biotech Co., Ltd., Beijing, China) was used to obtain PCR products from dried specimens, according to the manufacturer's instructions with some modifications (Chen et al. 2015a, 2016a). ITS4 and ITS5 were used as primers for ITS. LR0R and LR7 were used as primers for nLSU. The PCR procedure for ITS was as follows: initial denaturation at $95{ }^{\circ} \mathrm{C}$ for $5 \mathrm{~min}$, followed by 35 cycles at $94{ }^{\circ} \mathrm{C}$ for $40 \mathrm{~s}, 54{ }^{\circ} \mathrm{C}$ for $45 \mathrm{~s}$ and $72{ }^{\circ} \mathrm{C}$ for $1 \mathrm{~min}$, and a final extension of $72{ }^{\circ} \mathrm{C}$ for $10 \mathrm{~min}$. The PCR procedure for $\mathrm{nLSU}$ was as follows: initial denaturation at $94{ }^{\circ} \mathrm{C}$ for $5 \mathrm{~min}$, followed by 35 cycles at $94{ }^{\circ} \mathrm{C}$ for $30 \mathrm{~s}, 50{ }^{\circ} \mathrm{C}$ for $1 \mathrm{~min}$ and $72{ }^{\circ} \mathrm{C}$ for $1.5 \mathrm{~min}$, and a final extension of $72{ }^{\circ} \mathrm{C}$ for $10 \mathrm{~min}$. The PCR products were purified and sequenced in Beijing Genomics Institute, China, with the same primers.

\section{Phylogenetic analysis}

To explore the phylogenetic position of the two newly sequenced specimens, their ITS + nLSU sequences were compiled to part of the ITS + nLSU dataset from Ortiz-Santana et al. (2013). In addition, sequences from Chen \& Cui (2016) are also used in the current analysis. Fibroporia albicans B.K. Cui \& Yuan Y. Chen and F. vaillantii (DC.) Parmasto were selected as outgroups.

The dataset was aligned by BioEdit (Hall 1999) and then manually adjusted with ClustalX (Thompson et al. 1997). Sequence alignments were deposited at TreeBase (http://www.treebase.org; submission ID 20524). Phylogenetic analysis was done as in Zhao et al. $(2013,2015)$ and Chen et al. (2016b). Maximum parsimony (MP) analysis was applied to the ITS + nLSU dataset. The tree construction procedure was performed in PAUP* version 4.0b10 (Swofford 2002). All characters were equally weighted and gaps were treated as missing data. Trees were inferred using the heuristic search option with TBR branch swapping and 1,000 random sequence additions. Maxtrees were set to 5,000, branches of zero length were collapsed and all parsimonious trees were saved. Clade robustness was assessed using a bootstrap (BT) analysis with 1,000 replicates (Felsenstein 1985). Descriptive tree statistics tree length (TL), consistency index (CI), retention index (RI), rescaled consistency index (RC), and homoplasy index (HI) were calculated for each Maximum Parsimonious Tree (MPT) generated.

RAxML v.7.2.8 was used to construct maximum likelihood (ML) trees with GTR+G+I model of site substitution including estimation of Gamma-distributed rate heterogeneity and a proportion of invariant sites (Stamatakis 2006). The branch support was evaluated with bootstrapping method of 1000 replicates (Hillis \& Bull 1993).

MrModeltest 2.3 (Posada \& Crandall 1998, Nylander 2004) was used to determine the best-fit evolution model for the dataset for Bayesian inference (BI). BI was calculated with MrBayes3.1.2 (Ronquist \& Huelsenbeck 2003) with a general time reversible (GTR) model of DNA substitution and an invgamma distribution rate variation across sites. Four Markov chains were run for 2000,000 generations until the split deviation frequency value $<0.01$, and sampled every 100th generations. The burn-in was set to discard the first $25 \%$ of the trees. A majority rule consensus tree of all remaining trees was calculated.

Phylogenetic trees were visualized using Treeview (Page 1996). Branches that received bootstrap support for maximum likelihood (BS), maximum parsimony (MP) and Bayesian posterior 
probabilities (BPP) greater than or equal to $75 \%$ (BS and MP) and 0.95 (BPP) were considered as significantly supported, respectively.

Table 1 A list of species, specimens and GenBank accession number of sequences used in this study.

\begin{tabular}{|c|c|c|c|c|}
\hline \multirow{2}{*}{ Species } & \multirow{2}{*}{ Specimen/Strain No. } & \multirow{2}{*}{ Locality } & \multicolumn{2}{|c|}{ GenBank no. } \\
\hline & & & ITS & LSU \\
\hline Amyloporia carbonica & DAOM-F-8281-T & Canada & KC585239 & KC585061 \\
\hline Amyloporia carbonica & FP-105585-Sp & USA & KC585240 & KC585062 \\
\hline Antrodia favescens & Vlasák 0412/4J & USA & KC543129 & KC543129 \\
\hline Antrodia heteromorpha & Niemelä 2621 & Canada & KC543149 & KC543149 \\
\hline Antrodia heteromorpha & Dai 12755 & USA & KP715306 & KP715322 \\
\hline Antrodia hyalina & Spirin 2772 & Russia & JQ700283 & JQ700283 \\
\hline Antrodia infirma & Niemelä 7637 & Finland & KC595894 & KC595894 \\
\hline Antrodia infirma & Niemelä 7644 & Finland & KC595895 & KC595895 \\
\hline Antrodia juniperina & SRM-403-T & USA & KC585285 & KC585109 \\
\hline Antrodia juniperina & FP-105489-Sp & USA & KC585282 & KC585105 \\
\hline Antrodia leucaena & Pennanen 927 & Finland & JQ700278 & JQ700278 \\
\hline Antrodia leucaena & Dai 11398 & China & KX958179 & - \\
\hline Antrodia macra & Eriksson 1967 & Unknown & KR605810 & KR605749 \\
\hline Antrodia macra & Hottola 2729 & Finland & KC543135 & KC543135 \\
\hline Antrodia malicola & Miettinen 10595.1 & China & KC595896 & KC595896 \\
\hline Antrodia malicola & Cui 7754 & China & KX958180 & KX958184 \\
\hline Antrodia mappa & Niemelä 2669 & Canada & KC543130 & KC543130 \\
\hline Antrodia mappa & Penttila 11756 & Finland & KC543113 & KC543113 \\
\hline Antrodia mellita & Spirin 3315 & Russia & KC543140 & KC543140 \\
\hline Antrodia minuta & Miettinen X1317 & Russia & KC595900 & KC595900 \\
\hline Antrodia minuta & Spirin 2680 & Russia & КС595898 & KC595898 \\
\hline Antrodia monomitica & Dai 10630 & China & $\mathrm{KY} 421732^{\mathrm{a}}$ & KY421734 ${ }^{\mathrm{a}}$ \\
\hline Antrodia monomitica & Dai 16894 & China & KY421733 ${ }^{a}$ & KY421735 a \\
\hline Antrodia oleracea & HHB-5988-Sp & USA & KC585293 & KC585117 \\
\hline Antrodia oleracea & Mad-4907 & USA & KC585295 & KC585119 \\
\hline Antrodia primaeva & Miettinen 177 & Russia & JQ700272 & JQ700272 \\
\hline Antrodia pulvinascens & Miettinen 7488 & Finland & JQ700274 & JQ700274 \\
\hline Antrodia ramentacea & Marstad 274-09 & Norway & KC543138 & - \\
\hline Antrodia ramentacea & Dai 6118 & China & KC951178 & - \\
\hline Antrodia serialiformis & Miettinen 14816 & USA & JQ700290 & - \\
\hline Antrodia serialiformis & JK-2009a & USA & FJ788412 & - \\
\hline Antrodia serialis & Miettinen 12401 & Finland & JQ700271 & JQ700271 \\
\hline Antrodia serialis & Dai 7626 & China & KR605812 & KR605751 \\
\hline Antrodia serpens & Dai 7465 & Luxemburg & KR605813 & KR605752 \\
\hline Antrodia serpens & Miettinen X1370 & Slovakia & KC543143 & KC543143 \\
\hline Antrodia subserpens & Cui 8310 & China & KP715310 & KP715326 \\
\hline Antrodia subserpens & Dai 13233 & China & KP715309 & KP715325 \\
\hline Antrodia tanakae & Dai 11770 & China & KR605815 & KR605754 \\
\hline Antrodia tanakae & Yuan 1106 & China & KP715313 & KP715329 \\
\hline Antrodia tropica & Cui 6471 & China & JQ837939 & - \\
\hline Antrodia tropica & Dai 13434 & China & KX958181 & KX958185 \\
\hline Antrodia variiformis & Spirin 8406_2 & USA & KT995137 & KT995159 \\
\hline Daedalea dickinsii & Yuan 2685 & China & KP171201 & KP171223 \\
\hline
\end{tabular}




\begin{tabular}{lllll} 
Daedalea dickinsii & Yuan 2707 & China & KP171202 & KP171224 \\
Daedalea quercina & Dai 12152 & Czech & KP171207 & KP171229 \\
Daedalea quercina & Dai 12659 & Finland & KP171208 & KP171230 \\
Fibroporia albican & Cui 9464 & China & KC456250 & KR605758 \\
Fibroporia vaillantii & FP-90877-R & USA & KC585345 & KC585170 \\
Fomitopsis pinicola & Cui 10312 & China & KR605781 & KR605720 \\
Fomitopsis subtropica & Cui 10578 & China & KR605787 & KR605726 \\
Postia fragilis & Vlasák 0610_8 & Czech & JF950573 & - \\
Postia fragilis & Cui 10088 & China & KF699120 & KJ684977 \\
Postia lacteus & Miettinen X1378 & Finland & KC595938 & KC595938 \\
Postia lacteus & Miettinen X1391 & Finland & KC595939 & KC595939 \\
Postia placenta & Niemelä 7609 (GB) & Finland & JX109846 & JX109846 \\
Postia placenta & Miettinen X1351 & Finland & KC595950 & KC595950 \\
\hline a Sequens & & &
\end{tabular}

a Sequences newly generated in this study.

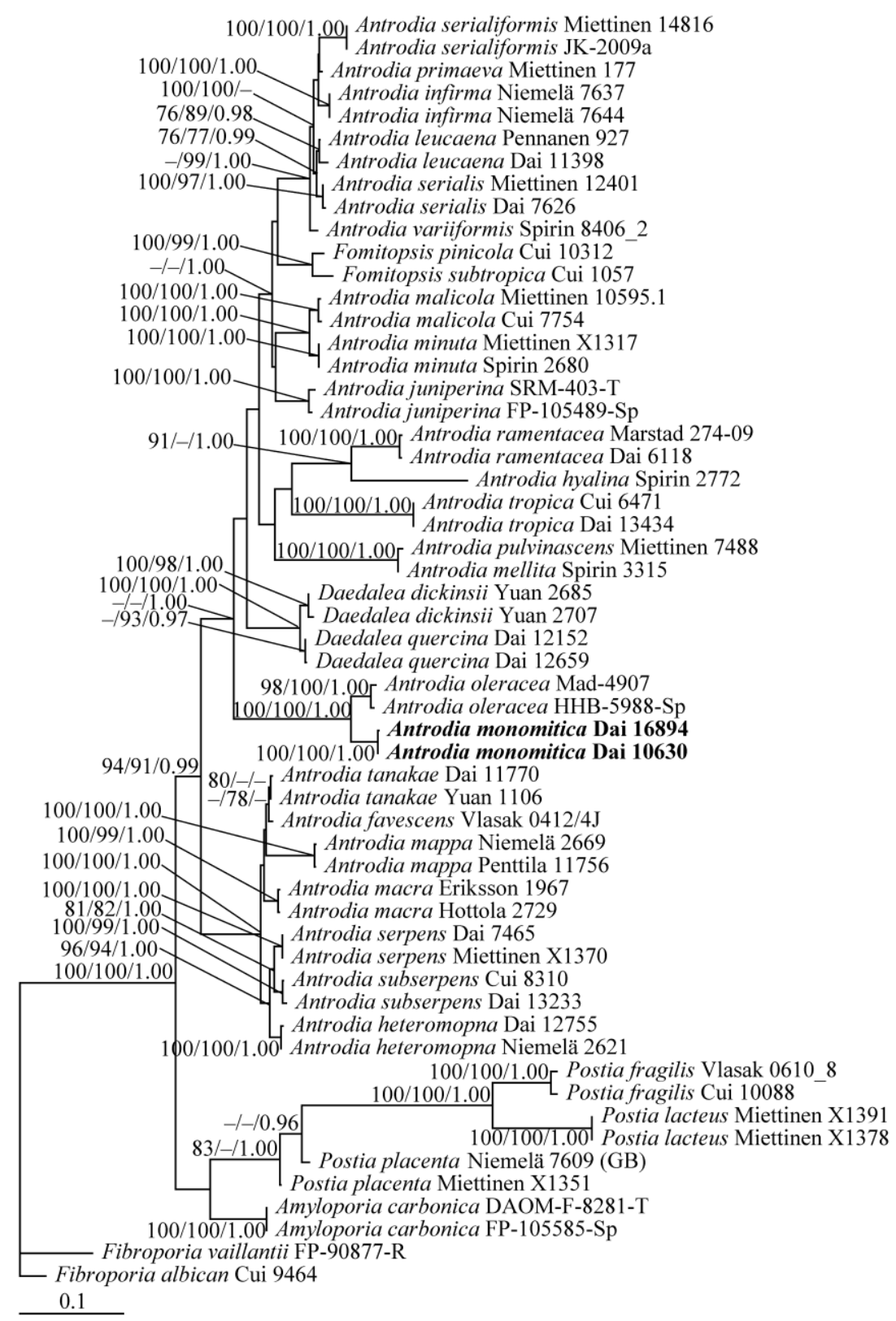

Fig. 1 - Phylogeny of Antrodia inferred from ITS + nLSU dataset. 


\section{Results}

\section{Phylogenetic analyses}

Two ITS and two nLSU sequences were newly generated for this study and their accession numbers are available in GenBank (Table 1).

The ITS + nLSU dataset included 48 specimens resulted in an alignment of 1613 characters, of which, 1127 characters are constant, 72 are variable and parsimony-uninformative, and 414 are parsimony informative characters. Maximum parsimony analysis yielded only one tree (TL $=1299$, $\mathrm{CI}=0.580, \mathrm{RI}=0.819, \mathrm{RC}=0.475, \mathrm{HI}=0.420)$. "GTR $+\mathrm{I}+\mathrm{G}$ " was the best-fit evolutionary model in the Bayesian analysis. The ML search stopped after 1000 BS replicates. All chains in BI converged after 2 million generations. ML and BI analyses yielded similar tree topologies with an average standard deviation of split frequencies $=0.008918$, and only the ML tree was provided. Both bootstrap values $(\geq 75 \%)$ and BPPs $(\geq 0.95)$ were showed at the nodes (Fig 1).

The phylogeny inferred from the ITS + nLSU dataset shows that the two newly sequenced specimens formed a terminal lineage within Antrodia s. 1. with full statistical supports (100\% BS, 1 BPP) and clustered with A. oleracea (R.W. Davidson \& Lombard) Ryvarden.

\section{Taxonomy}

Antrodia monomitica Yuan Y. Chen, sp. nov.

Figs 2-3

MycoBank number: MB 819955; Facesoffungi number: FoF 03384

Etymology - Monomitica (Lat.): referring to the monomitic hyphal structure of the species.

Known distribution -A rare species spread in subtropical and temperate regions of China.

Material examined - CHINA, Heilongjiang Prov., Harbin, the Campus of Harbin University of Science and Technology, on rotten wood of Morus, 6 Aug 2016, Y.C. Dai, Dai 16894 (BJFC 22529, holotype).

Fruiting body - Basidiomata annual, resupinate, nodulose without real cap, up to $10 \mathrm{~cm}$ long, $6 \mathrm{~cm}$ wide and $3 \mathrm{~cm}$ thick at centre; fleshy when fresh, chalky and fragile upon drying. Pore surface white to cream when fresh, cream, buff or cinnamon buff upon drying; sterile margin white, very narrow to almost lacking; pores round to angular, 3-4 per mm; dissepiments thin, entire to slightly lacerate. Subiculum white, fleshy when fresh, chalky to fragile upon drying, up to $2 \mathrm{~cm}$ thick. Tubes concolorous with the pore surface, chalky, up to $1 \mathrm{~cm}$ long.

Hyphal structure - Hyphal system monomitic; generative hyphae bearing clamp connections, IKI-, $\mathrm{CB}-$; tissues unchanged in $\mathrm{KOH}$.

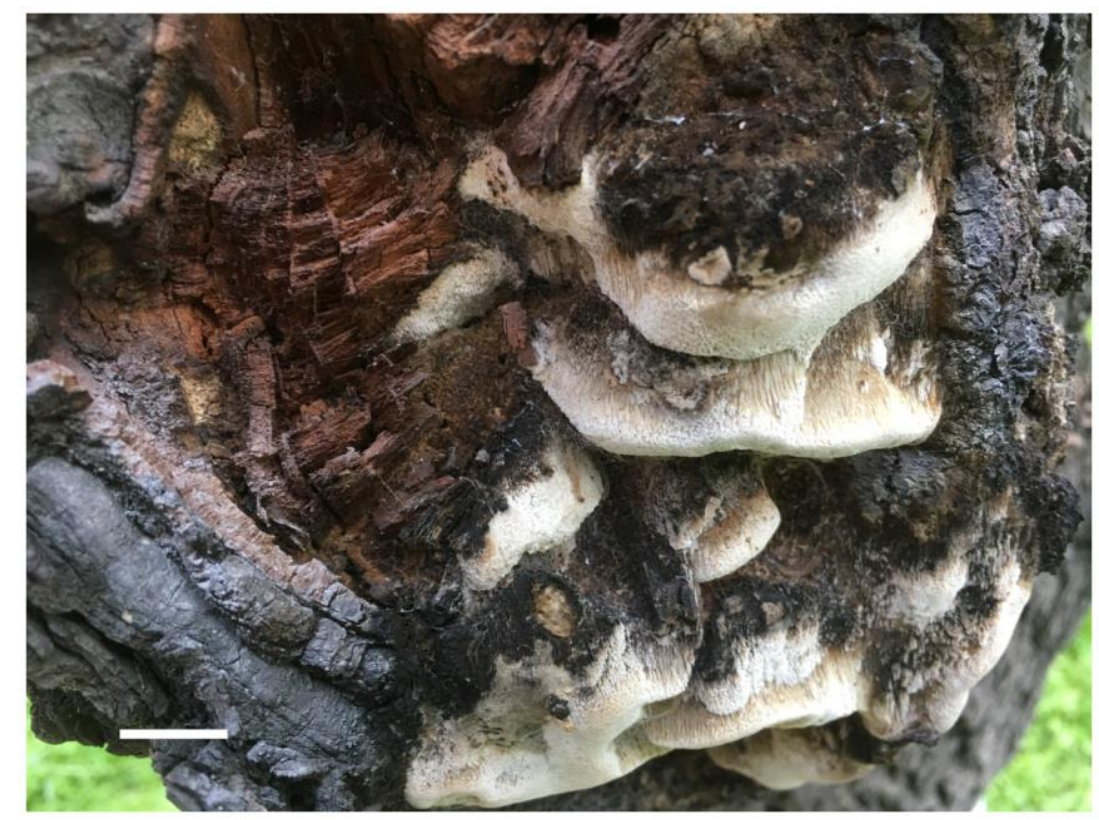

Fig. 2 - Basidiomata of Antrodia monomitica (BJFC 22529). - Bars = $10 \mathrm{~mm}$. 
Subiculum - Generative hyphae hyaline, thin- to slightly thick-walled, frequently branched some bearing fine crystals, flexuous, interwoven, 3-8 $\mu \mathrm{m}$ in diam, some inflated up to $11 \mu \mathrm{m}$ in diam.

Tubes - Generative hyphae hyaline, thin- to slightly thick-walled, occasionally branched, interwoven, 2-6 $\mu \mathrm{m}$ in diam. Cystidia absent; cystidioles present, fusoid, thin-walled, $12-15 \times 3.5-$ $4 \mu \mathrm{m}$. Basidia clavate, with four sterigmata and a basal clamp connection, 14-20 × 5-6.5 $\mu \mathrm{m}$; basidioles in shape similar to basidia, but slightly smaller.

Spores - Basidiospores fusiform to mango-shaped, hyaline, thin-walled, smooth, sometimes with one guttule, IKI-, CB-, 6-7.5(-8) $\times 2.3-3 \mu \mathrm{m}, \mathrm{L}=6.62 \mu \mathrm{m}, \mathrm{W}=2.68 \mu \mathrm{m}, \mathrm{Q}=2.44-2.51(\mathrm{n}$ $=60 / 2$ ).

Additional specimen examined - CHINA, Jiangxi Prov., Nanchang, Forest Park of Jiangxi Academy of Forestry, on rotten angiosperm wood, 24 Sept 2008, Y.C. Dai, Dai 10630 (BJFC 004879, paratype).

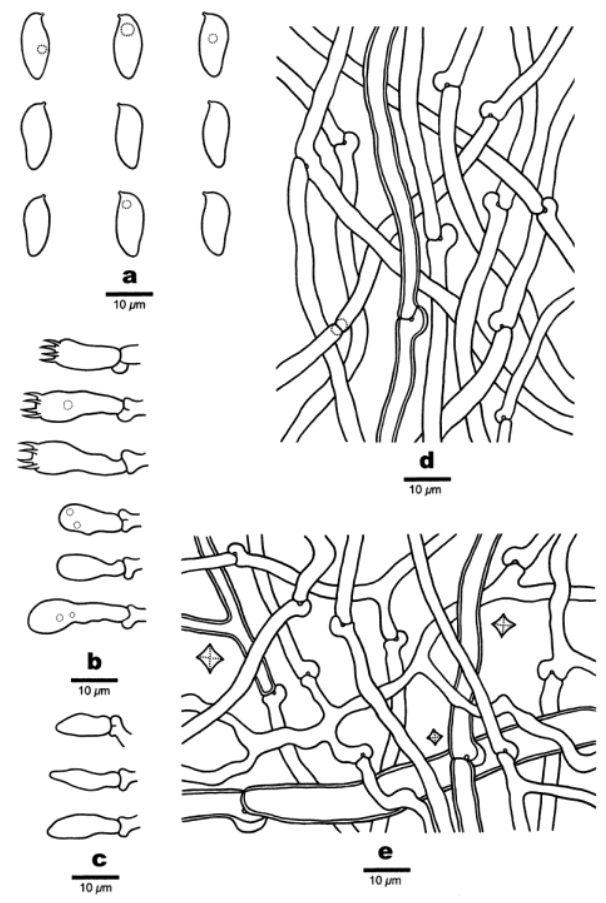

Fig. 3 - Microscopic structures of Antrodia monomitica (draw from the holotype). a: Basidiospores; b: Basidia and basidioles; c: Cystidioles; d: Hyphae from trama; e: Hyphae from subiculum. - Bars $=10 \mu \mathrm{m}$.

\section{Discussion}

Antrodia monomitica is characterized by annual, resupinate to nodulose basidiomata which becoming fragile upon drying, a monomitic hyphal structure with clamp connections on generative hyphae, hyaline, thin-walled and fusiform to mango-shaped basidiospores $(6-7.5 \times 2.3-3 \mu \mathrm{m})$, and causing a typical brown rot.

Morphologically, Antrodia monomitica is similar to species of Postia Fr. because of its annual fruiting bodies, a monomitic hyphal system with clamp connections on generative hyphae and causing a brown rot. However, Postia species have allantoid to cylindrical basidiospores, and they belong to different lineages in the phylogenetic analysis (Shen \& Cui 2014, Shen et al. 2014, 2015).

Phylogenetic analysis based on ITS and nLSU regions indicated Antrodia monomitica belongs to Antrodia s. 1. with full statistical supports and has a closer relationship with A. oleracea. However, A. oleracea is different in having much thinner basidiomata, a dimitic hyphal system and cylindrical to oblong ellipsoid basidiospores (Ryvarden \& Johansen 1980).

Amyloporia carbonica (Overh.) Vampola \& Pouzar and Antrodia leucaena Y.C. Dai \& Niemelä have white basidiomata and similar pore size, and they somehow resemble Antrodia 
monomitica in morphology, but Amyloporia carbonica has distinctly amyloid skeletal hyphae and wider cylindrical basidiospores $(6-7.5 \times 2.8-4 \mu \mathrm{m})$ and growing on dead conifer wood (Henrici \& Ryvarden 1997, Ryvarden \& Melo 2014); Antrodia leucaena is distinguished from Antrodia monomitica in having thinner basidiomata, a dimitic hyphal system and narrowly ellipsoid to subcylindrical basidiospores (Dai \& Niemelä 2002, Ryvarden \& Melo 2014). Besides, these three species clustered in different lineages in the phylogenetic analysis.

\section{Acknowledgements}

We express our gratitude to Prof. Yu-Cheng Dai (BJFC, China) allowed us to study his specimens and Dr. Bao-Kai Cui (BJFC, China) for improving the manuscript. The research was financed by the Fundamental Research Funds for the Central Universities (Project No. 2016ZCQ04) and the National Science and Technology Foundation Project of China (Project No. 2014FY210400).

\section{References}

Bernicchia A, Gorjón SP, Vampola P, Ryvarden L, Prodi A. 2012 - A phylogenetic analysis of Antrodia s. 1. based on nrDNA ITS sequences, with emphasis on rhizomorphic European species. Mycological Progress 11, 93-100.

Chen JJ, Cui BK, Zhou LW, Korhonen K, Dai YC. 2015a - Phylogeny, divergence time estimation, and biogeography of the genus Heterobasidion (Basidiomycota, Russulales). Fungal Diversity 71, 185-200.

Chen YY, Li HJ, Cui BK. 2015b - Molecular phylogeny and taxonomy of Fibroporia in China. Phytotaxa 203, 47-54.

Chen JJ, Cui BK, Dai YC. 2016a - Global diversity and molecular systematics of Wrightoporia s. 1. (Russulales, Basidiomycota). Persoonia 37, 21-36.

Chen JJ, Cui BK, He SH, Cooper JA, Barrett MD, Chen JL, Dai YC. 2016b - Molecular phylogeny and global diversity of the remarkable genus Bondarzewia (Basidiomycota, Russulales). Mycologia 108, 697-708.

Chen YY, Cui BK. 2016 - Phylogenetic analysis and taxonomy of the Antrodia heteromorpha complex in China. Mycoscience 57, 1-10.

Cui BK. 2013 - Antrodia tropica sp. nov. from southern China inferred from morphological characters and molecular data. Mycological Progress 12, 223-230.

Cui BK, Dai YC. 2013 - Molecular phylogeny and morphology reveal a new species of Amyloporia (Basidiomycota) from China. Antonie Van Leeuwenhoek 104, 817-827.

Dai YC, Niemelä T. 2002 - Changbai wood-rotting fungi 13. Antrodia sensu lato. Annales Botanici Fennici 39, 257-265.

Donk MA. 1960 - The generic names proposed for Polyporaceae. Persoonia 1, 173-302.

Felsenstein J. 1985 - Confidence intervals on phylogenies: an approach using the bootstrap. Evolution 39, 783-791.

Han ML, Chen YY, Shen LL, Song J, Vlasák J, Dai YC, Cui BK. 2016 - Taxonomy and phylogeny of the brown-rot fungi: Fomitopsis and its related genera. Fungal Diversity 80, 343-373.

Hall TA. 1999 - BioEdit: a user-friendly biological sequence alignment editor and analysis program for Windows 95/98/NT. Nucleic Acids Symposium Series 41, 95-98.

Henrici A, Ryvarden L. 1997 - Antrodia pseudosinuosa sp. nov. Mycologist 11, 152-153.

Hillis DM, Bull JJ. 1993 - An empirical test of bootstrapping as a method for assessing confidence in phylogenetic analysis. Systematic Biology 42, 182-192.

Kim SY, Park SY, Ko KS, Jung HS. 2003 - Phylogenetic analysis of Antrodia and related taxa based on partial mitochondrial SSU rDNA sequences. Antonie van Leeuwenhoek 83, 81-88.

Li HJ, Cui BK, Dai YC. 2014 - Taxonomy and multi-gene phylogeny of Datronia (Polyporales, Basidiomycota). Persoonia 32, 170-182. 
Nylander JAA. 2004 - MrModeltest v2. Program distributed by the author. Evolutionary Biology Centre, Uppsala University.

Ortiz-Santana B, Lindner DL, Miettinen O, Justo A, Hibbett DS. 2013 - A phylogenetic overview of the antrodia clade (Basidiomycota, Polyporales). Mycologia 105, 1391-1411.

Page RMD. 1996 - Treeview: an application to display phylogenetic trees on personal computers. Computer Applications in the Biosciences Cabios 12, 357-358.

Petersen JH. 1996 - The Danish Mycological Society's colour-chart. Foreningen til Svampekundskabens Fremme, Greve.

Posada D, Crandall KA. 1998 - Modeltest: testing the model of DNA substitution. Bioinformatics $14,817-818$.

Rajchenberg M, Gorjón SP, Pildain MB. 2011 - The phylogenetic disposition of Antrodia s. 1. (Polyporales, Basidiomycota) from Patagonia Argentina. Australian Systematic Botany 24, 111-120.

Ronquist F, Huelsenbeck JP. 2003 - MRBAYES 3: Bayesian phylogenetic inference under mixed models. Bioinformatics 19, 1572-1574.

Ryvarden L, Johansen I. 1980 - A preliminary polypore flora of East Africa. Fungiflora, Oslo. pp. 1-636.

Ryvarden L. 1991 - Genera of polypores. Nomenclature and taxonomy. Synopsis Fungorum 5, 1363.

Ryvarden L, Melo I. 2014 - Poroid fungi of Europe. Synopsis Fungorum 31, 1-455.

Shen LL, Cui BK. 2014 - Morphological and molecular evidence for a new species of Postia (Basidiomycota) from China. Cryptogamie Mycologie 35, 199-207.

Shen LL, Cui BK, Dai YC. 2014 - A new species of Postia (Polyporales, Basidiomycota) from China based on morphological and molecular evidence. Phytotaxa 162, 147-156.

Shen LL, Liu HX, Cui BK. 2015 - Morphological characters and molecular data reveal two new species of Postia (Basidiomycota) from China. Mycological Progress 14, 7.

Spirin V, Miettinen O, Pennanen J, Kotiranta H, Niemela T. 2012 - Antrodia hyalina, a new polypore from Russia, and A. leucaena, new to Europe. Mycological Progress 12, 53-61.

Spirin V, Vlasák J, Niemelä T, Miettinen O. 2013 - What is Antrodia sensu stricto? Mycologia 105, 1555-1576.

Spirin V, Runnel K, Vlasák J, Miettinen O, Põldmaa K. 2015 - Species diversity in the Antrodia crassa group (Polyporales, Basidiomycota). Fungal Biology 119, 1291-1310.

Spirin V, Vlasák J, Niemelä T, Miettinen O. 2016 - Hidden diversity in the Antrodia malicola group (Polyporales, Basidiomycota). Mycological Progress 15, 1-12.

Stamatakis A. 2006 - RAxML-VI-HPC: maximum likelihood-based phylogenetic analysis with thousands of taxa and mixed models. Bioinformatics 22, 2688-2690.

Swofford DL. 2002 - PAUP*: phylogenetic analysis using parsimony (*and other methods). version 4.0b10. Sinauer Associates, Sunderland.

Thompson JD, Gibson TJ, Plewniak F, Jeanmougin F, Higgins DG. 1997 - The Clustal_X windows interface: flexible strategies for multiple sequence alignment aided by quality analysis tools. Nucleic Acids Research 25, 4876-4882.

$\mathrm{Yu} \mathrm{ZH}, \mathrm{Wu}$ SH, Wang DM, Chen CT. 2010 - Phylogenetic relationships of Antrodia species and related taxa based on analyses of nuclear large subunit ribosomal DNA sequences. Botanic Studies 51, 53-60.

Zhao CL, Cui BK, Dai YC. 2013 - New species and phylogeny of Perenniporia based on morphological and molecular characters. Fungal Diversity 58, 47-60.

Zhao CL, Cui BK, Song J, Dai YC. 2015 - Fragiliporiaceae, a new family of Polyporales (Basidiomycota). Fungal Diversity 70, 115-126. 